\title{
Evaluating the effect of processing parameters on the replication quality in the micro compression molding of silicone rubber
}

\author{
K. Maghsoudi*, E. Vazirinasab, R. Jafari, G. Momen \\ Department of Applied Sciences, University of Quebec in Chicoutimi (UQAC) \\ 555, boul. de l'Université, Chicoutimi, Québec, G7H 2B1, Canada \\ *E-mail: Khosrow.maghsoudil@uqac.ca
}

\begin{abstract}
Given the role of micro-nanostructures in producing superhydrophobic and icephobic surfaces and the importance of high-quality replication of these micro-nanostructures in direct replication processes, we evaluated the effect of processing parameters on the superhydrophobicity, icephobicity, and replication quality of silicone rubber surfaces created via micro-compression molding. Molding pressure, mold temperature, curing time, and part thickness were selected as the processing parameters to be assessed. We used a response surface methodology to illustrate the optimal values of the selected processing parameters. Molding pressure and part thickness were the main influencing parameters to attain the superhydrophobicity. In a second set of experiments, we assessed the replication quality of silicone rubber surfaces of variable thickness subjected to different molding pressures. Each part thickness had an optimal molding pressure for obtaining the best replication quality. Surfaces having the highest replication quality also demonstrated the longest freezing delay and confirmed their potential use as anti-icing surfaces. Although all developed superhydrophobic surfaces showed icephobicity, the influence of processing parameters affecting ice adhesion was complex.
\end{abstract}

\section{Keywords:}

Processing; Parameters; Compression; Molding; Replication; Silicone; Microstructure; Superhydrophobicity; Icephobicity.

\section{Introduction}

Various processing techniques exist for fabricating polymer materials that have a specifically desired size and shape at the micro- or nanoscale. These techniques include micro-injection molding, micro-compression molding, hot embossing, casting, and 3D printing. ${ }^{[1,2]}$ Among these, 
micro-injection molding, micro-compression molding, and hot embossing are the most industrially desirable mass-production processes for microfabrication because they offer high repeatability, lower fabrication costs, faster cycle times, the simultaneous shaping of bulk and surface structures, and comparatively simple automation. ${ }^{[1,3]}$

The most critical aspect of the microfabrication process is achieving the required high precision. The level of precision is affected by several parameters, including the geometry and the thickness of the product, surface structure size, the aspect ratio of the structures, the positioning of the structures in relation to the direction of polymer flow, and the processing parameters. The processing parameters have the most influence on precision and include mold and melt temperatures, packing pressure, flow velocity, and holding time. ${ }^{[4]}$ The role of each parameter may differ depending on the selected material and applied microfabrication technique; for example, the role of melt temperature differs greatly between the microfabrication of thermoplastics and that of rubber materials. An increased melt temperature reduces the viscosity of the thermoplastic, which is advantageous for obtaining a high-quality replication. ${ }^{[5]}$ In contrast, the melt temperature in rubber processing must be kept as low as possible as an elevated temperature increases the rate of crosslinking. Any crosslinking before the filling of the cavity reduces the filling quality. ${ }^{[1,6]}$ Hopmann et al. ${ }^{[6]}$ showed that to successfully achieve desired surface structures in the microinjection molding of liquid silicone rubber (LSR), the rubber curing should be delayed as much as possible. The best results were obtained by using higher injection speeds and lower mold and melt temperatures. As another example, the holding time in the micro-injection molding of thermoplastics defines the cooling time of the material. However for rubber micro-compression molding, holding time determines the curing time of the rubber, and both have critical effects on the quality of the final parts. In some cases, to realize the desired surface structures, a combination of both thermoplastic and rubber has been used. ${ }^{[7]}$ First, the microtextures were transferred from an aluminum template to the polycarbonate (PC) surface and then from the PC to the polydimethylsiloxane (PDMS).

In the microfabrication of parts having micro-nanostructured surfaces, the thickness of the substrate is markedly greater than that of the micro-nanostructures. A thicker substrate hinders the increase of the in-cavity pressure; this results in a poorer replication quality, whereas a thinner substrate — by allowing the in-cavity pressure to increase — leads to a higher quality of filling. ${ }^{[8]}$ 
As the combination of different processing parameters can lead to contradictory effects on the final product, the manipulation of microfabrication processing parameters is complicated.

At present, investigations of the effects of processing parameters on microfabrication processes have been limited mainly to the micro-injection molding of thermoplastics, such as polymethyl methacrylate (PMMA) ${ }^{[9]}$, polystyrene $(\mathrm{PS})^{[8]}$, polypropylene $(\mathrm{PP})^{[10]}$, and polyethylene $(\mathrm{PE})^{[11]}$. Although some studies have investigated the microfabrication of rubber materials, e.g., liquid silicone rubber $(\mathrm{LSR})^{[6]}$, or rubber-containing polymers, such as thermoplastic elastomers $(\mathrm{TPE})^{[12,13]}$, there remains a lack of comprehensive research on the microfabrication of rubber materials. As such, to our knowledge, this study examines, for the first time, the influence of molding processing parameters on the superhydrophobic and icephobic properties of micronanostructured silicone rubber surfaces via a statistical assessment.

For a material to show superhydrophobic properties, i.e., a water contact angle (CA) of $>150^{\circ}$ and a sliding angle (SA) of $<10^{\circ}$, it should possess hydrophobic characteristics, and the surface should also include micro-nanostructures that roughen the surface. ${ }^{[14]}$ These micro-nanostructures should be arranged so that a water droplet cannot penetrate the surface features because of the entrapped air in the cavities, a state called the Cassie-Baxter regime. Otherwise, the water droplet penetrates into the surface features and the Wenzel regime dominates. ${ }^{[15]}$ The abovementioned microfabrication techniques are appealing for mass producing superhydrophobic surfaces. ${ }^{[16-18]}$ The produced superhydrophobic surfaces can potentially delay ice formation (anti-icing) and reduce the formed ice adhesion strength (de-icing).

The increased probability of a coupling reaction between two macromolecules - produced from radical-radical recombination and macroradical addition-can create a "crosslinked" network structure. ${ }^{[19,20]}$ The crosslink density (CD) is defined as the number of crosslinked points per unit volume, expressed in $\mathrm{mol} \cdot \mathrm{cm}^{-3}{ }^{[21]}$ The vulcanization reaction (crosslinking) respects the classical law of chemical reaction kinetics, and hence it is dominated by the process temperature. ${ }^{[22]}$ By increasing curing temperature or curing time, the physical and mechanical properties may deteriorate due to the overcuring. ${ }^{[22]}$ Therefore, the CD can affect the demolding quality, physical properties, and mechanical properties of the cured rubber. 
The principal objective of this study is to evaluate the effect of processing parameters on the superhydrophobic and icephobic properties and the replication quality of silicone rubber materials produced using micro-compression molding. We selected molding pressure, mold temperature, curing time, and part thickness to evaluate the optimal combination of parameters via a DoE method. The produced output response surface maps allow the results to be used in decisionmaking for fabricating superhydrophobic/icephobic silicone rubber surfaces.

\section{Materials and methods}

High-temperature vulcanized (HTV) silicone rubber (SR) was used as the process material. A wetchemical-etching method produced the aluminum (A6061) templates. The aluminum sheets were cut into intended size and cleaned in acetone and distilled water for 20 min ultrasonically. After drying at $70{ }^{\circ} \mathrm{C}$ for $1 \mathrm{~h}$, they were chemically etched using a $15 \mathrm{wt} . \%$ hydrochloric acid solution for $2 \mathrm{~h}$. Then, the templates were cleaned ultrasonically with distilled water for $30 \mathrm{~min}$ and dried at $70{ }^{\circ} \mathrm{C}$ for $1 \mathrm{~h}$. We used a micro-compression molding machine (Carver Inc. USA) having two temperature-adjustable platens. The hydraulic press system is capable of controlling precisely an applied force of 3 to $194 \mathrm{kN}$. Three-piece flat molds, all having a right rectangular prism cavity of $25 \times 25 \mathrm{~mm}^{2}$ with various thicknesses $(3 \mathrm{~mm}, 6 \mathrm{~mm}, 9 \mathrm{~mm}$ ), cast the rubber materials. The template was placed on the lower part of the mold into the cavity, and the rubber material was placed onto the template. The top the mold was then closed. The mold was set in the press machine to begin the process. To determine an appropriate process window, we undertook an initial familiarization set of experiments. For this, we determined the most extreme levels at which an acceptable result could be attained. DoE then selected those processing parameters to be assessed for the experimental runs. After the process, the mold was opened, and the cured SR was detached from the aluminum template. Fig. 1 schematically represents the direct replication process to create micro-nanostructures on the SR through a micro-compression molding system using a three-piece flat mold. It is worth noting that we used a fluorochemical-based release agent to ensure a flawless demolding for acquiring a high-quality micro-nanostructured surface. 


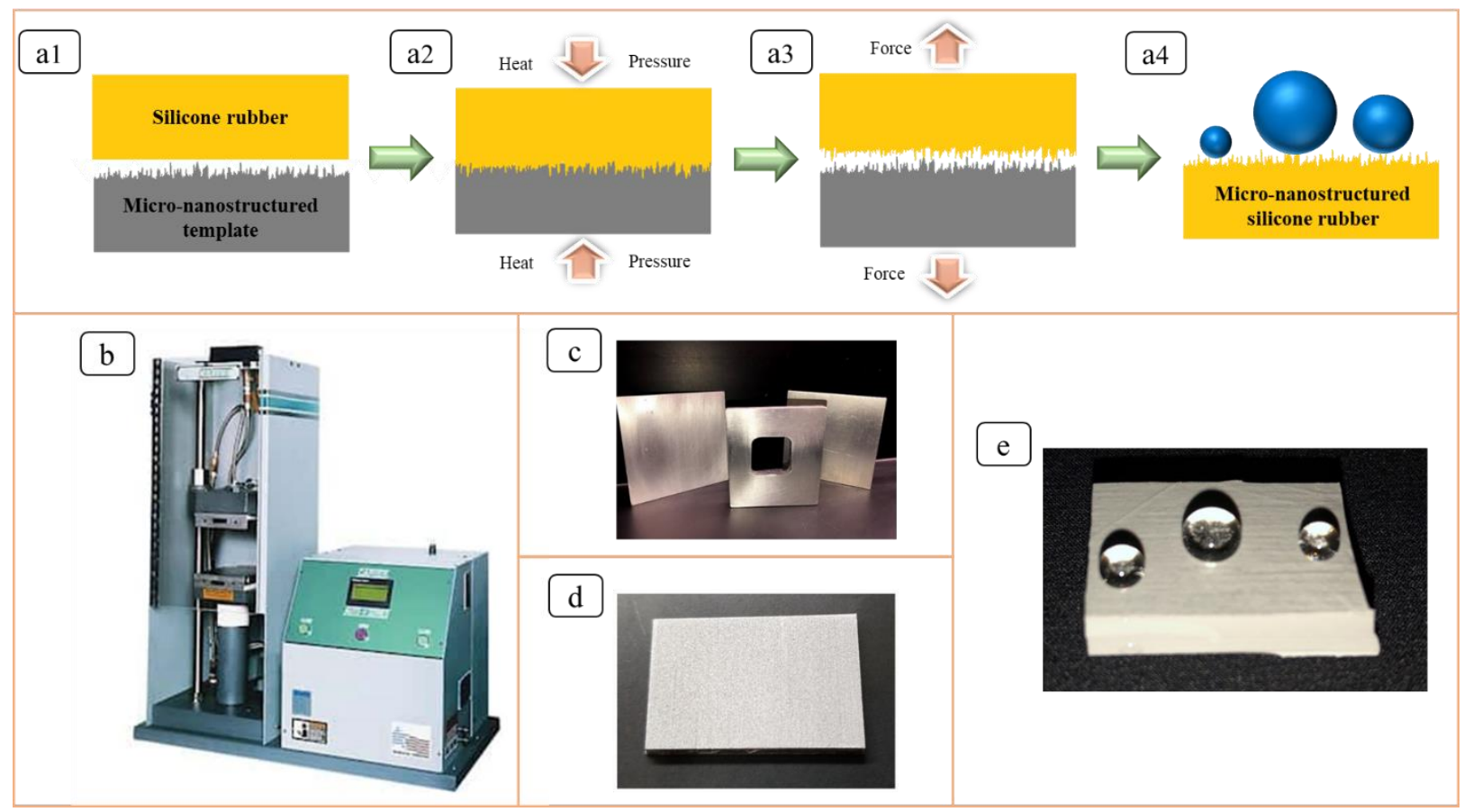

Fig. 1. Schema of the direct replication process: (a1) material placement, (a2) molding under heat and pressure, (a3) demolding, and (a4) the replicated micro-nanostructured silicone rubber superhydrophobic behavior; photographs of the $(b)$ microcompression molding system; (c) three-piece mold; (d) micro-nanostructured aluminum template; and (e) replicated superhydrophobic silicone rubber surface.

We used a D-optimal method to optimize the combination of the multi-level factors. The curing time $\left(t_{c}\right)$ is 4-level factor varying from $1.5 \mathrm{~min}$ to $9 \mathrm{~min}$. For the molding pressure $(P)$, four levels, from $5 \mathrm{MPa}$ to $50 \mathrm{MPa}$ with a $15-\mathrm{MPa}$ interval, were selected. The mold temperature $\left(T_{w}\right)$ is 3 level factor varying from $120{ }^{\circ} \mathrm{C}$ to $180{ }^{\circ} \mathrm{C}$. Three thicknesses of $3 \mathrm{~mm}, 6 \mathrm{~mm}$, and $9 \mathrm{~mm}$ were selected as the part thickness $(d)$ (Table 1). In running the design, the number of experimental runs decreased from $144(4 \times 4 \times 3 \times 3)$ to 53 runs. The processing parameters of each of the 53 experimental runs are provided in Table $\mathrm{S} 1$.

Table 1. Different levels of the processing parameters.

\begin{tabular}{lllll}
\hline Factor & \multicolumn{4}{c}{ Level } \\
\hline $\boldsymbol{t}_{\boldsymbol{c}}(\mathbf{m i n})$ & 1.5 & 3 & 6 & 9 \\
$\boldsymbol{P}(\mathbf{M P a})$ & 5 & 20 & 35 & 50 \\
$\boldsymbol{T}_{\boldsymbol{w}}\left({ }^{\circ} \mathbf{C}\right)$ & 120 & 150 & 180 & - \\
$\boldsymbol{d}(\mathbf{m m})$ & 3 & 6 & 9 & - \\
\hline
\end{tabular}


The water CA was measured using a goniometer (Kruss $\left.{ }^{\mathrm{TM}} \mathrm{DSA} 100\right)$ at $25^{\circ} \mathrm{C} \pm 0.5{ }^{\circ} \mathrm{C}$ based on the Young-Laplace approximation. The used deionized water droplet had a volume of $4 \mu \mathrm{L}$. We used a tilting plate capable to adjust the angle from $0^{\circ}$ to $90^{\circ}$ to determine the $\mathrm{SA}$. We recorded the SA when the droplet began to slide or roll off the surface. To ensure the accuracy and reproducibility of our results, all wettability measurements were conducted at five different points on each sample; we report the average for each sample. We observed the morphology of the fabricated SR surfaces using a scanning electron microscope (SEM, JSM-6480 LV by JEOL Japan). We evaluated the surface chemical compositions using Fourier transform infrared spectroscopy (FTIR) and the energy dispersive X-ray spectroscopy (EDS). The surface roughness of the molded SR samples was evaluated by the area surface roughness values, i.e., root mean square roughness $\left(\mathrm{S}_{\mathrm{q}}\right)$, skewness $\left(\mathrm{S}_{\mathrm{sk}}\right)$, and kurtosis $\left(\mathrm{S}_{\mathrm{ku}}\right)$ provided by a confocal laser microscopy profiler (Profil3D, Filmetrics, USA). The $\mathrm{S}_{\mathrm{q}}$ is defined as the standard deviation of the distribution of surface heights. ${ }^{[23]}$ The skewness coefficient shows the symmetry level of the surface height relative to the mean plane. ${ }^{[24,25]}$ Therefore, a surface with a fully symmetrical height distribution has zero skewness, a surface having more peaks than valleys has positive skewness, and a surface possessing more valleys than peaks has negative skewness. ${ }^{[23,26]}$ The sharpness of the probability density of the surface profile is described by the kurtosis coefficient. A jagged surface (high peaks and low valleys) usually has $S_{\mathrm{ku}}>3$, while a relatively flatter surface shows a $S_{\mathrm{ku}}<3$. ${ }^{[23]}$

The CD of the cured SR samples was measured via a swelling experiment. The sample arrived at an equilibrium swollen state in toluene at room temperature for $72 \mathrm{~h}$. The sample was weighed immediately after removing from the toluene $\left(m_{1}\right)$. The sample was then dried at $60{ }^{\circ} \mathrm{C}$ for $24 \mathrm{~h}$ and was weighed $\left(m_{2}\right)$. Given the density of rubber $\left(\rho_{r}=1.15 \mathrm{~g} / \mathrm{cm}^{3}\right)$ and the density of toluene $\left(\rho_{s}\right.$ $\left.=0.866 \mathrm{~g} / \mathrm{cm}^{3}\right)$, the volume fraction of the SR in the swollen sample was calculated using the following equation ${ }^{[27]}$ :

$\varphi=\frac{\left(\frac{m_{2}}{\rho_{r}}\right)}{\left(\frac{m_{2}}{\rho_{r}}\right)+\left(\frac{m_{1}-m_{2}}{\rho_{s}}\right)}$.

Therefore, the CD $(v)$ and $M_{c}$ were calculated according to the Flory-Rehner theory ${ }^{[28]}$ :

$v=\frac{-\left(\ln (1-\varphi)+\varphi+\chi \varphi^{2}\right)}{V\left(\varphi^{\frac{1}{3}}-\frac{\varphi}{2}\right)}$ 
$M_{C}=\frac{\rho_{r}}{v}$

where $\chi$ is the Flory-Hoggins polymer-solvent interaction coefficient, calculated as $\chi=0.459+$ $0.134 \varphi+0.59 \varphi^{2}$, and $V$ is the molar volume of toluene $(106.7 \mathrm{~mL} / \mathrm{mol})$.

We measured the freezing delay time using the cold chamber of goniometer machine. The Peltier cooling controller (sample stage) is capable of reaching $-30{ }^{\circ} \mathrm{C}$ with a control precision of $0.1^{\circ} \mathrm{C}$. The 4- $\mu \mathrm{L}$ water droplet, being filmed by the goniometer camera, was transparent upon its placement on the surface. With time, the droplet became non-transparent, representing the frozen state. The delay time of this state change was recorded as the freezing delay. Ice adhesion strength was determined using a push-off instrument. A thin cylindrical, 1-cm diameter plastic mold was placed on the sample and filled with deionized water. The ice formed after the mold was placed in a cold chamber at $-10{ }^{\circ} \mathrm{C}$ for $24 \mathrm{~h}$ prior to testing. The de-icing process was conducted where the sample holder was pushed toward the force gauge at a rate of $0.05 \mathrm{~mm} \cdot \mathrm{s}^{-1}$ until the ice detached from the surface. The force was recorded at the moment of ice detachment.

\section{Results and discussion}

To evaluate the effect of processing parameters on the superhydrophobic and physical properties of the produced surface, we used CA, SA, and CD as the measured responses. The results for the produced surfaces are presented in Table 2 . The CA, SA, and CD vary from $148.7^{\circ}$ to $169.6^{\circ}, 1.0^{\circ}$ to $21.7^{\circ}$, and $2.89 \times 10^{-4} \mathrm{~mol} / \mathrm{cm}^{3}$ to $4.71 \times 10^{-4} \mathrm{~mol} / \mathrm{cm}^{3}$, respectively, throughout the experiments. The analysis of variance (ANOVA) is discussed in the supplementary. 
Table 2. The contact angle (CA), sliding angle (SA), and crosslink density (CD) of the produced surfaces.

\begin{tabular}{|c|c|c|c|c|c|c|c|}
\hline \multicolumn{5}{|c|}{ Responses } & \multicolumn{3}{|c|}{ Responses } \\
\hline $\begin{array}{l}\text { Run } \\
\text { no. }\end{array}$ & CA $\left(^{\circ}\right)$ & $\mathbf{S A}\left(^{\circ}\right)$ & $\begin{array}{l}\mathrm{CD} \times 10^{4} \\
\left(\mathrm{~mol} / \mathrm{cm}^{3}\right)\end{array}$ & Run no. & CA $\left(^{\circ}\right)$ & $\mathbf{S A}\left(^{\circ}\right)$ & $\begin{array}{l}\mathrm{CD} \times 10^{4} \\
\left(\mathrm{~mol} / \mathrm{cm}^{3}\right)\end{array}$ \\
\hline 1 & 160.2 & 5.3 & 3.94 & 28 & 166.0 & 3.3 & 3.73 \\
\hline 2 & 161.9 & 3.7 & 4.39 & 29 & 160.3 & 4.7 & 3.05 \\
\hline 3 & 160.2 & 4.7 & 4.41 & 30 & 161.9 & 3.7 & 4.28 \\
\hline 4 & 155.7 & 6.7 & 3.63 & 31 & 161.3 & 3.7 & 4.63 \\
\hline 5 & 163.5 & 3.3 & 4.18 & 32 & 164.0 & 2.0 & 4.52 \\
\hline 6 & 162.9 & 3.7 & 4.54 & 33 & 159.6 & 5.7 & 3.07 \\
\hline 7 & 163.1 & 3.7 & 3.42 & 34 & 148.7 & 21.7 & 4.02 \\
\hline 8 & 155.0 & 7.7 & 2.89 & 35 & 154.4 & 17.3 & 4.17 \\
\hline 9 & 158.4 & 7.3 & 4.09 & 36 & 150.1 & 18.7 & 4.42 \\
\hline 10 & 156.6 & 8.0 & 4.31 & 37 & 152.8 & 19.7 & 3.69 \\
\hline 11 & 159.6 & 4.0 & 4.71 & 38 & 151.1 & 15.0 & 2.94 \\
\hline 12 & 158.0 & 6.3 & 4.68 & 39 & 154.6 & 9.3 & 4.28 \\
\hline 13 & 161.9 & 3.0 & 3.77 & 40 & 155.3 & 7.7 & 4.29 \\
\hline 14 & 158.4 & 5.7 & 4.23 & 41 & 155.7 & 7.7 & 4.48 \\
\hline 15 & 162.8 & 4.7 & 4.29 & 42 & 156.6 & 7.0 & 4.56 \\
\hline 16 & 157.5 & 5.3 & 4.34 & 43 & 155.7 & 4.3 & 3.41 \\
\hline 17 & 155.0 & 7.7 & 3.18 & 44 & 154.9 & 12.7 & 3.35 \\
\hline 18 & 155.6 & 8.3 & 4.16 & 45 & 158.7 & 5.7 & 4.4 \\
\hline 19 & 159.5 & 15.3 & 4.49 & 46 & 156.6 & 2.3 & 4.49 \\
\hline 20 & 156.3 & 6.7 & 4.5 & 47 & 160.3 & 3.0 & 4.61 \\
\hline 21 & 157.7 & 11.0 & 3.25 & 48 & 159.8 & 3.3 & 3.47 \\
\hline 22 & 159.1 & 7.0 & 4.15 & 49 & 162.7 & 2.7 & 4.47 \\
\hline 23 & 159.5 & 7.3 & 4.16 & 50 & 161.2 & 2.0 & 4.53 \\
\hline 24 & 158.6 & 4.7 & 4.51 & 51 & 162.6 & 2.7 & 4.5 \\
\hline 25 & 157.2 & 3.0 & 3.96 & 52 & 160.3 & 3.7 & 4.16 \\
\hline 26 & 165.6 & 1.3 & 4.13 & 53 & 162.0 & 6.7 & 3.98 \\
\hline 27 & 169.6 & 1.0 & 4.26 & & & & \\
\hline
\end{tabular}

Effect of processing parameters on the $\mathrm{CA}, \mathrm{SA}$, and $\mathrm{CD}$

To better illustrate our results, we present the predicted models as 3D response surface plots. For the CA, molding pressure (hereinafter pressure), part thickness (hereinafter thickness), their interaction, and the interaction between thickness and curing time (hereinafter time) were significant model terms. The 3D response surface relationship between thickness and pressure for $\mathrm{CA}$ at the center level of time and mold temperature (hereinafter temperature), i.e., $5.3 \mathrm{~min}$ and $150{ }^{\circ} \mathrm{C}$, respectively, is presented in Fig. 2(a). Maximum CA was achieved in the upper half of the 
pressure range and at the center level of thickness. By increasing thickness, the required pressure for achieving a higher CA increased. At higher thickness values, the CA monotonically increased with pressure. At lower thickness values, however, a maximum CA was produced at an optimal pressure. Therefore, increasing pressure does not necessarily lead to a higher CA for all thicknesses. This pattern can be ascribed to the destructive effect of high pressure on the template micro-nanostructures at the lower thickness.

According to the interaction between thickness and time, the highest CA values were attained at a thickness of $\leq 6 \mathrm{~mm}$ and a time of $\leq 6 \mathrm{~min}$. To obtain a high $\mathrm{CA}$, therefore, both thickness and time should be selected from the lower values. We observed the same results for the interaction between thickness and time when pressure was altered. The 3D response surface relationships between thickness and time for CA at various pressure levels are presented in Fig. S1.

As such, we can conclude that pressure has the greatest effect on the achievable CA; however, higher pressure does not necessarily lead to a higher CA. The optimal pressure level depends on part thickness. It is also recommended to select as low of a processing duration as possible from within the optimal range.

The same parameters, i.e., thickness and pressure, their interactions, and the interaction between thickness and time are significant model factors for the SA. Our aim was to achieve as low a SA as possible. Fig. 2(b) illustrates that the lowest SAs were achieved at pressure values between $\sim 14$ $\mathrm{MPa}$ and $\sim 41 \mathrm{MPa}$ for a thickness of $3 \mathrm{~mm}$. By increasing the thickness, however, a higher pressure was required to maintain a low SA. The thickness-time graphs at various levels of pressure are presented in Fig. S2. We obtained the lowest SA when both thickness and time tended toward their minimal values, as observed for CA. The highest level of pressure led to ultra-low SAs, especially for the thicker samples.

The modulus of rubber at small elongations is essentially proportional to rubber $\mathrm{CD} .{ }^{[21]}$ The relationship between Young's modulus $(E)$ and the average molecular mass of the crosslink points $\left(M_{c}\right)$ at small strains is stated as ${ }^{[29]}$ :

$E=3 v k T=3 \rho R T / M_{c}$, 
where $v$ is the number of chains per unit volume, i.e., CD, $k$ is Boltzmann's constant, $T$ is the absolute temperature, $\rho$ is the density of rubber, and $R$ is gas constant. As such, a lower $M_{c}$, which corresponds to a higher $\mathrm{CD}$, leads to a greater Young's modulus.

We found that all processing parameters were significant terms for modeling the CD. However of these terms, time, temperature, and their interaction were most significant. The 3D response surface relationship between temperature and time on the $\mathrm{CD}$ at the center level of pressure and thickness demonstrates an optimal value for temperature for achieving the highest CD at a given time (Fig. 2(c)). Thus, by increasing temperature, the CD increased due to the increased crosslinking (vulcanization) reaction rate. A high curing temperature enhanced the decomposition rate of the vulcanizing agent to produce more free radicals ${ }^{[30]}$; this led in general to a higher CD. However, increasing the curing temperature beyond the optimal value caused the CD to be reduced due to the dominance of chain scission at higher temperatures. 

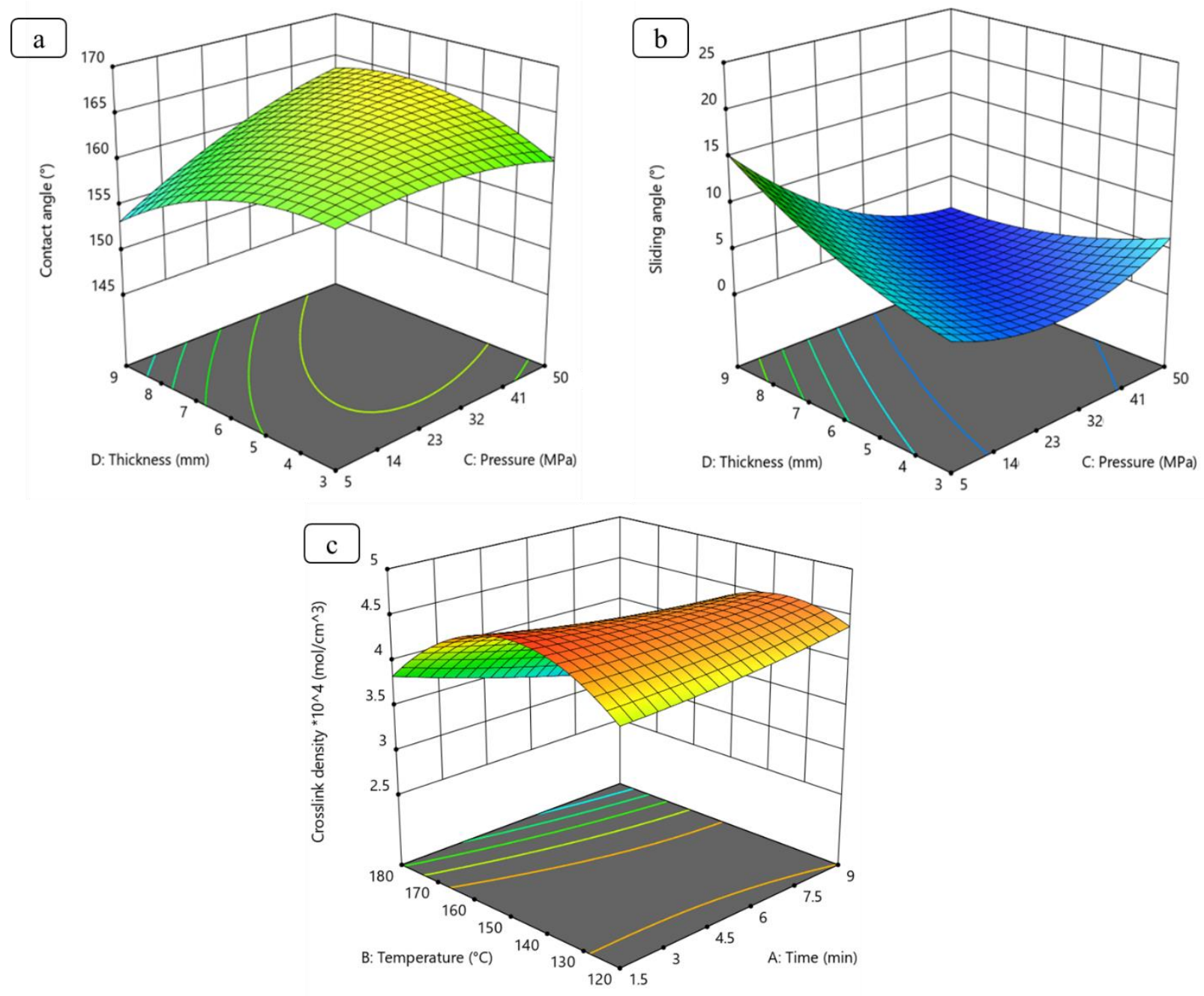

Fig. 2. The 3D response surface relationship between (a) part thickness and molding pressure on the CA at the center level of mold temperature and curing time, (b) part thickness and molding pressure on the SA at the center level of mold temperature and curing time; and (c) mold temperature and curing time on the CD at the center level of molding pressure and part thickness.

Surface characterization based on the optimal model

Using the processing parameters obtained from the optimal model, i.e., curing time of $4.7 \mathrm{~min}$, mold temperature of $149^{\circ} \mathrm{C}$, molding pressure of $49.7 \mathrm{MPa}$, and thickness of $7.4 \mathrm{~mm}$, we produced a pristine and a superhydrophobic SR surface. Fig. 3 shows SEM images, EDS and FTIR spectra results of the produced surfaces. The produced surface roughness as required structures to create superhydrophobicity is evident. According to the model, the fabricated surface using the optimal parameters should possess a CA of $164.6^{\circ}$ and a SA of $1.4^{\circ}$. We observed a CA of $165.1^{\circ} \pm 0.6^{\circ}$ and a SA of $1.6^{\circ} \pm 0.2^{\circ}$. These results, therefore, confirmed the predicted optimal model. FTIR absorption spectra of $\mathrm{Si}\left(\mathrm{CH}_{3}\right)_{2}, \mathrm{Si}-\mathrm{O}-\mathrm{Si}, \mathrm{Si}\left(\mathrm{CH}_{3}\right)$, and $\mathrm{Si}(\mathrm{OH})$ at positions $805-855 \mathrm{~cm}^{-1}, 1000$ $1110 \mathrm{~cm}^{-1}, 1245-1275 \mathrm{~cm}^{-1}$, and $3500-3700 \mathrm{~cm}^{-1}$, respectively, were observed for pristine and 
superhydrophobic SR surfaces. ${ }^{[31]}$ Also, EDS spectra results showed the similar peaks, i.e., C, O, $\mathrm{Al}$, and Si having an almost identical atomic percentage for pristine and superhydrophobic SR surfaces. Therefore, FTIR and EDS spectra results confirmed that the replication process did not altered the SR surface chemically.

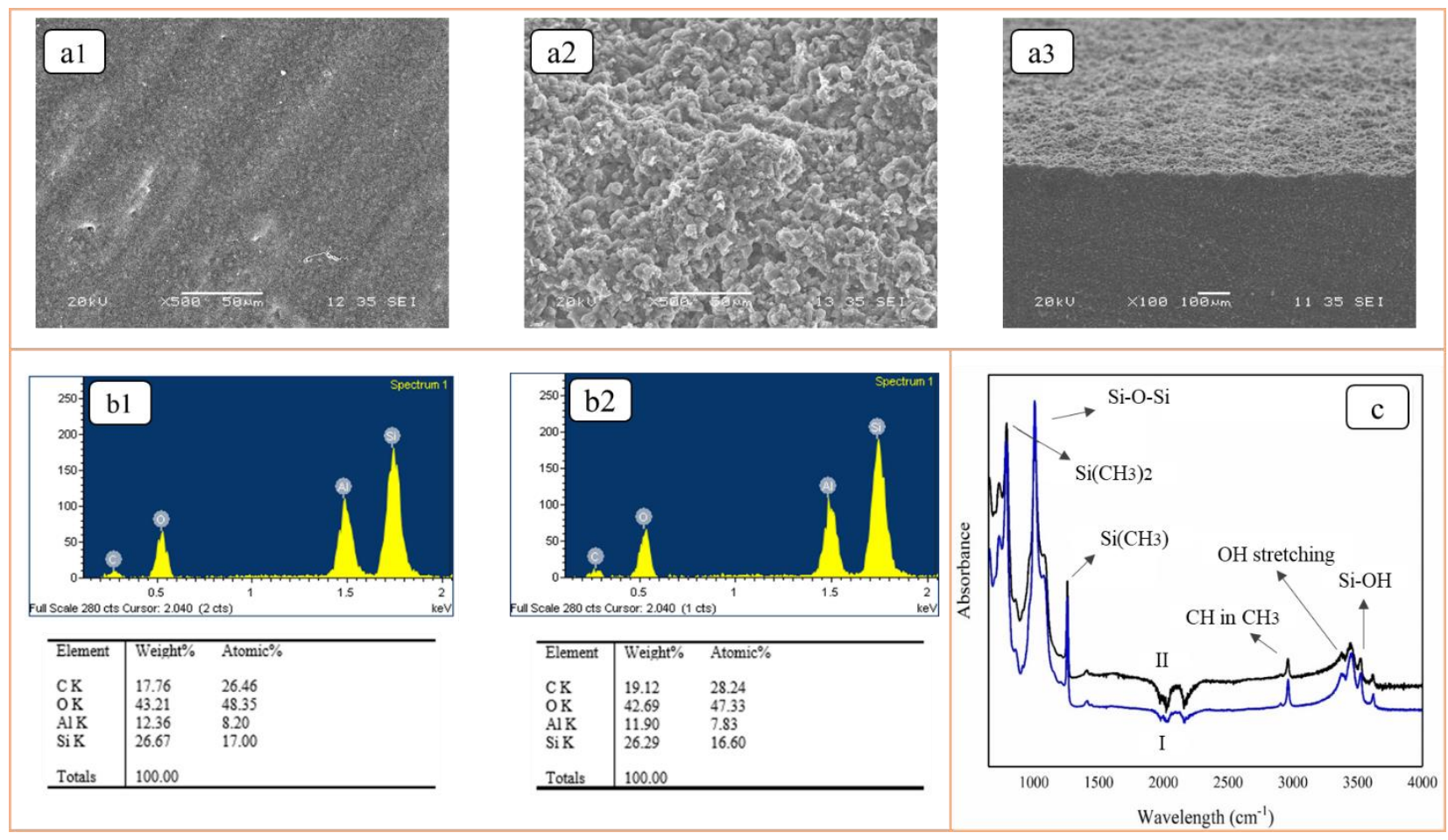

Fig. 3. SEM images of (a1) pristine, (a2) top view and (a3) cross view of superhydrophobic SR surfaces; EDS spectra results of (b1) pristine, (b2) superhydrophobic SR surfaces; and (c) FTIR spectra for (I) pristine, (II) superhydrophobic SR surfaces.

Effect of the significant factors on replication quality (RQ)

We investigated the effect of two significant factors controlling wettability, i.e., thickness and pressure, on RQ. Three levels were considered for each factor: pressures of 20, 35, and $50 \mathrm{MPa}$ and thicknesses of 3,6, and $9 \mathrm{~mm}$. Table 3 shows the effect of pressure and thickness on the RQ and CA at a fixed time and temperature $\left(4.7 \mathrm{~min}\right.$ and $149.0^{\circ} \mathrm{C}$, respectively) based on the optimal model. RQ is expressed as the root mean square area roughness value $\left(S_{\mathrm{q}}\right)$ for each sample compared to that of an aluminum template. As the produced surfaces have a $\mathrm{CA}>150^{\circ}$ and a SA $<10^{\circ}$, the dominant wetting regime is Cassie-Baxter. Therefore, the area fraction of solid-liquid interface $(f)$ was calculated according to the following equation ${ }^{[32]}$ :

$\cos \theta_{C}=f\left(1+\cos \theta_{Y}\right)-1$, 
where $\theta_{C}$ is the Cassie-Baxter apparent CA, and $\theta_{Y}$ is the intrinsic CA (for pristine $\mathrm{SR}, \theta_{Y}$ is $116^{\circ}$ $\left.\pm 2.0^{\circ}\right)$.

Table 3. The effect of molding pressure and part thickness on the replication quality $(R Q)$ and surface wettability of the produced surfaces.

\begin{tabular}{|c|c|c|c|c|c|c|c|c|c|}
\hline \multirow[b]{2}{*}{ Sample } & \multicolumn{2}{|c|}{ Processing parameter } & \multicolumn{4}{|c|}{ Surface roughness parameter } & \multicolumn{3}{|c|}{ Surface wettability } \\
\hline & $\begin{array}{l}\text { Molding } \\
\text { pressure } \\
\text { (MPa) }\end{array}$ & $\begin{array}{l}\text { Part } \\
\text { thickness } \\
(\mathrm{mm})\end{array}$ & $\mathbf{S}_{\mathbf{q}}(\boldsymbol{\mu m})$ & Skewness & Kurtosis & RQ (\%) & CA $\left(^{\circ}\right)$ & SA $\left(^{\circ}\right)$ & $f(\%)$ \\
\hline $\begin{array}{l}\mathrm{Al} \\
\text { template }\end{array}$ & - & - & 10.450 & 0.235 & 2.997 & - & - & - & - \\
\hline S1 & 20 & 3 & 9.749 & 0.067 & 3.743 & 93.29 & $\begin{array}{l}168.8 \pm \\
0.7\end{array}$ & $\begin{array}{l}3.0 \pm \\
0.6\end{array}$ & 3.39 \\
\hline S2 & 35 & 3 & 8.747 & -0.137 & 2.510 & 83.70 & $\begin{array}{l}167.8 \pm \\
0.8\end{array}$ & $\begin{array}{l}3.0 \pm \\
0.6\end{array}$ & 4.02 \\
\hline S3 & 50 & 3 & 7.444 & -0.232 & 2.615 & 71.23 & $\begin{array}{l}0.0 \\
167.3 \pm \\
1.1\end{array}$ & $\begin{array}{l}.0 \\
5.3 \pm \\
1.3\end{array}$ & 4.36 \\
\hline S4 & 20 & 6 & 7.406 & -0.428 & 3.008 & 70.87 & $\begin{array}{l}163.8 \pm \\
1.2\end{array}$ & $\begin{array}{l}4.3 \pm \\
1.6\end{array}$ & 7.07 \\
\hline S5 & 35 & 6 & 10.020 & 0.067 & 3.795 & 95.89 & $\begin{array}{l}169.3 \pm \\
0.9\end{array}$ & $\begin{array}{l}1.7 \pm \\
0.3\end{array}$ & 3.10 \\
\hline S6 & 50 & 6 & 8.317 & 0.097 & 3.743 & 79.59 & $\begin{array}{l}166.3 \pm \\
1.6\end{array}$ & $\begin{array}{l}3.7 \pm \\
0.6\end{array}$ & 5.07 \\
\hline S7 & 20 & 9 & 7.150 & -0.317 & 2.295 & 68.42 & $\begin{array}{l}158.3 \pm \\
0.5\end{array}$ & $\begin{array}{l}9.3 \pm \\
0.9\end{array}$ & 12.62 \\
\hline S8 & 35 & 9 & 7.551 & -0.267 & 3.134 & 72.26 & $\begin{array}{l}159.6 \pm \\
0.6\end{array}$ & $\begin{array}{l}5.7 \pm \\
0.6\end{array}$ & 11.17 \\
\hline S9 & 50 & 9 & 9.403 & -0.245 & 3.408 & 89.98 & $\begin{array}{l}161.5 \pm \\
0.7\end{array}$ & $\begin{array}{l}.0 \\
3.3 \pm \\
0.3\end{array}$ & 9.20 \\
\hline
\end{tabular}

RQs ranging from $\sim 70 \%$ to $\sim 96 \%$ were obtained by altering pressure and thickness. In terms of $\mathrm{RQ}$ and the associated wettability values, the higher the RQ, the greater the superhydrophobicity. A high-quality replication therefore led to higher $\mathrm{CA}$ and lower SA values due to the most appropriate roughness being created on the SR surface. For example, the highest CA $\left(169.3^{\circ}\right)$ and the lowest SA $\left(1.7^{\circ}\right)$ were obtained when RQ was $95.89 \%$ (S5). Fig. 4 presents the 3D surface profiles of all produced samples having different RQs. The 3D surface profile of the aluminum template can be found in the supplementary (Fig. S3).

For 3-mm thickness, RQ decreased as pressure increased; therefore, the highest RQ was obtained at $20 \mathrm{MPa}$ (Sample S1). This reduction in RQ stemmed from the destructive effect of the pressure on the template micro-nanostructures as the higher pressures caused the micro-nanostructures on the template surface to be compressed and result in a relatively flatter SR surface. For example, 
Sample S3 had a kurtosis value of $<3$, whereas Sample S1 had near-zero skewness and a kurtosis $>3$.

Optimal RQ for the 6-mm thick samples was attained at the moderate pressure values, i.e., $35 \mathrm{MPa}$. The 20-MPa pressure was not sufficient for the rubber material to fill the structures, while the 50MPa pressure (Sample S6) had a slight destructive effect on the micro-nanostructures. Sample S5 had the highest CA and the lowest SA values among all samples due to its highest RQ (95.89\%) and the most near-zero skewness values (0.067).

For the 9-mm thick samples, CA increased as pressure increased, and higher pressures produced a higher RQ. The SR material did not successfully replicate the micro-nanostructures at the 20-MPa pressure (Sample S7). The kurtosis of Sample S7 was <3 reflecting a rather flat surface. Moreover, it also had the highest skewness, indicating a non-symmetrical surface. Thus, a proper pressure profile was not established in the cavity, resulting in a non-symmetrical surface at the siliconetemplate interface that increased the probability of pinning a water droplet rolling across the surface. Hence, Sample S7 recorded the highest SA $\left(9.3^{\circ}\right)$. 

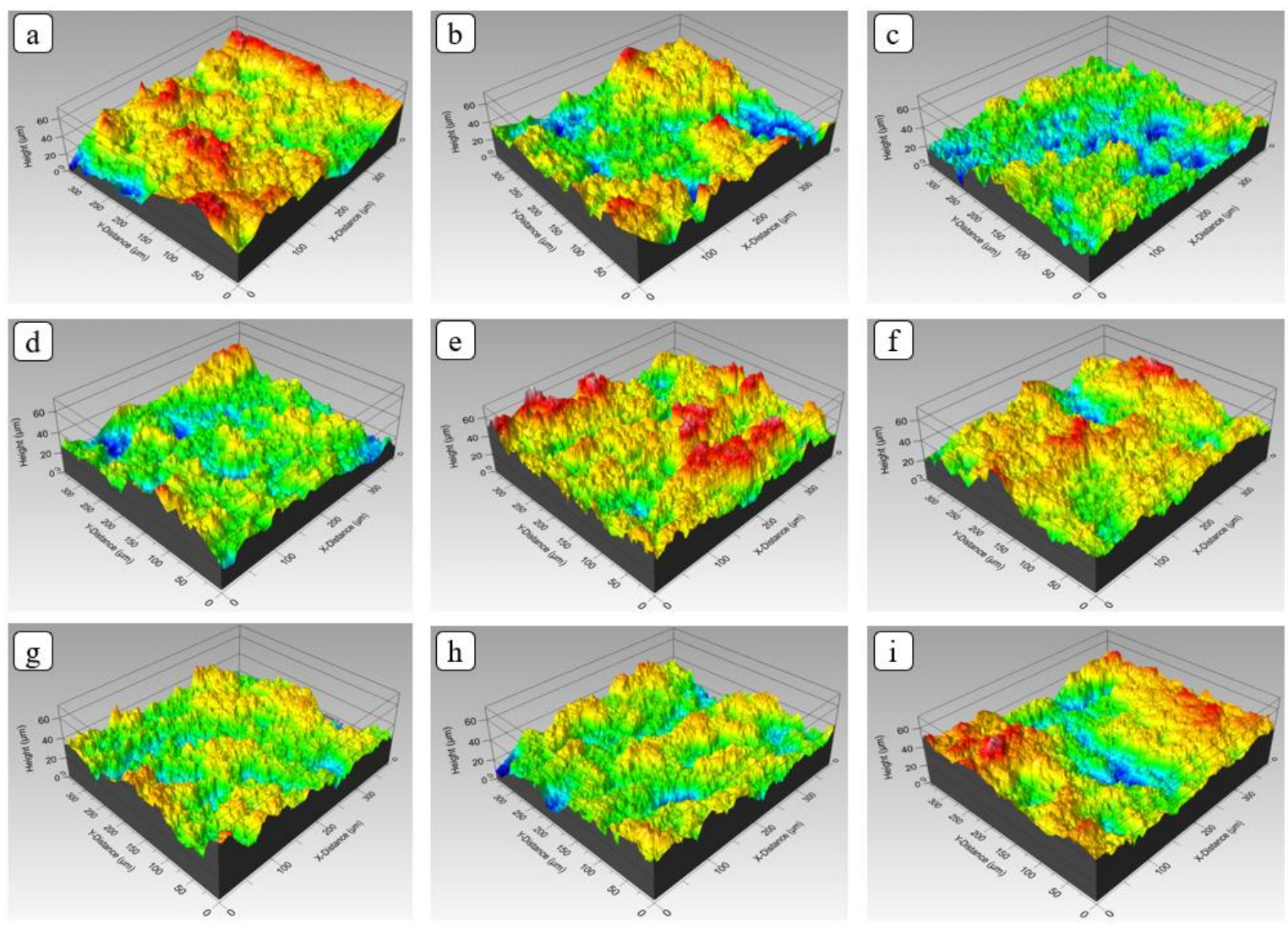

Fig. 4. The $3 D$ surface profiles of samples (a) S1, (b) S2, (c) S3, (d) $S 4$, (e) $S 5$, (f) S6, ( $g$ ) S7, (h) S8, and (i) S9 representing various replication qualities. See Table 3 for details of the molding pressure and part thickness of each sample.

\section{Icephobicity}

The fabrication of icephobic materials targets two main objectives: (i) preventing or decreasing the accumulation of ice on a substrate and (ii) reducing the ice adhesion strength. ${ }^{[33]}$ To evaluate the first property, the freezing delay time can be used as a criterion, while the assessment of the second property relies on the ice adhesion strength test.

\section{Freezing delay}

For samples at $-25^{\circ} \mathrm{C}$, freezing delay times were affected by the solid-liquid area fraction of the Cassie-Baxter equation $(f)$ obtained from the CA (Fig. 5(a)). Surfaces having a lower solid-liquid interface, i.e., higher liquid-gas interface, showed longer freezing delays due to the lower heat dissipation along the surface derived from a higher CA.

As there is a direct relationship between the volume of micro-air cavities that act as thermal insulation and the delay in droplet freezing ${ }^{[34]}$, the trapped air volume in the micro-cavities was calculated using the profilometry technique. Fig. 5(a) shows the $V_{\text {superhydrophobic }} / V_{\text {pristine }}$ value, i.e., 
the ratio between the trapped air volume in the fabricated superhydrophobic surface to that of the pristine surface. A higher $\mathrm{V}_{\text {superhydrophobic }} / \mathrm{V}_{\text {pristine }}$ resulted in the longer freezing delay due to less heat loss through the surface asperities.

All superhydrophobic surfaces demonstrated an enhanced anti-icing behavior compared to that of the pristine surface. A $2.24 \times-3.91 \times$ enhancement was observed for the various superhydrophobic surfaces. The high volume of entrapped air (representing the liquid-gas interface) acts in concert with the low solid-liquid area fraction $(f)$ to delay ice formation. Samples S5, S6, and S1, having the lowest $f$ values, highest kurtosis, and highest $\mathrm{V}_{\text {superhydrophobic }} / \mathrm{V}_{\text {pristine values, demonstrated the }}$ best anti-icing capabilities. Sample $\mathrm{S} 7$, characterized by a high $f$ and a low $\mathrm{V}_{\text {superhydrophobic }} / \mathrm{V}_{\text {pristine }}$ value, produced the slowest freezing time among the superhydrophobic surfaces. This result demonstrated the importance of replication quality when comparing the $74 \%$ increase in the freezing delay of the Sample S5 $(\mathrm{RQ}=\sim 96 \%)$ with Sample S7 $(\mathrm{RQ}=68 \%)$.

\section{Ice adhesion strength}

The icephobic enhancement percentage was determined as the reduced ice adhesion strength compared to that of the pristine surface. As shown in Fig. 5(b), the icephobic enhancement percentage of superhydrophobic surfaces was significant (35\% to 62\%). However, among the superhydrophobic samples, Sample S2 showed the lowest ice adhesion strength $(69.3 \mathrm{kPa})$ and the highest de-icing enhancement percentage (62\%).

Ice adhesion strength was influenced by the kurtosis and the solid-liquid area fraction $(f)$, but not in a straight-forward manner. The mechanical interlocking between the ice and the surface structures plays a vital role in ice adhesion. ${ }^{[25,35]}$ Therefore, for surfaces having relatively higher peaks and lower valleys, i.e., higher kurtosis, the probability of this mechanical interlocking is greater. On the other hand, a lower solid-liquid area fraction leads to less contact area between surface and the water, thereby reducing the interlocked area. Sample S2, having relatively low kurtosis and $f$ values, produced the highest de-icing enhancement percentage. Although a surface having lower kurtosis is normally more favorable for producing de-icing properties, this is contingent on a low $f$ value. For example, Sample S7 that had a low kurtosis value (2.295) also showed a relatively high ice adhesion strength, which was attributed to its high $f$ value. In such a case, although the surface is relatively flatter and the probability of mechanical interlocking is less 
due to the lower kurtosis, the higher $f$ value led to a higher contact area and thus a higher ice adhesion strength.
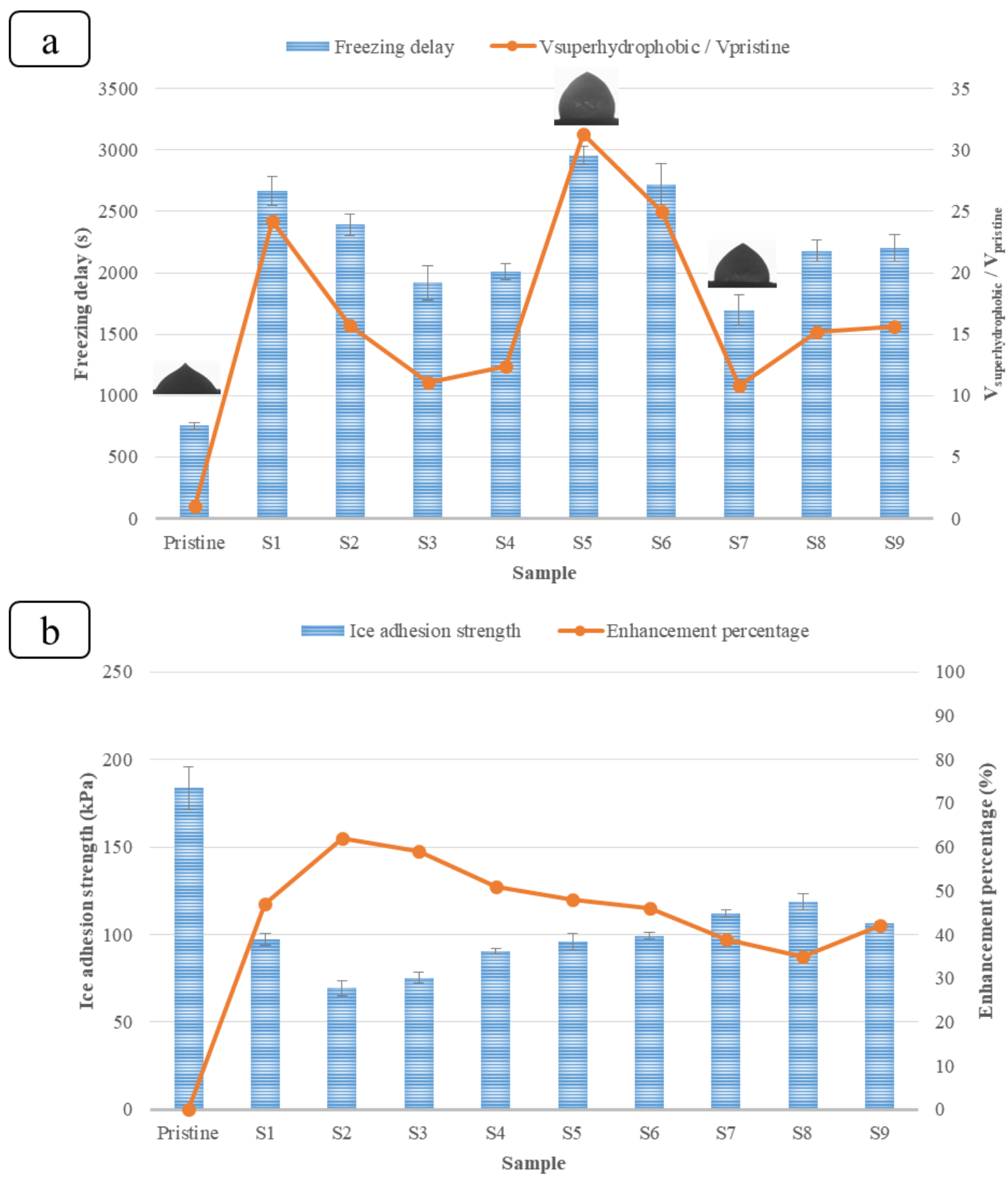

Fig. 5. (a) Freezing delay and the increased entrapped air pockets ratios for the samples at $-25^{\circ} \mathrm{C}$. Inset images represent the droplets at the moment of complete freezing for the pristine surface, Sample S5, and Sample S7. (b) Ice adhesion strength and deicing enhancement percentage of the various samples. 


\section{Conclusion}

The fabrication of SR having micro-nanostructures to achieve superhydrophobic and icephobic properties via a micro-compression molding technique is highly susceptible to the processing parameters. Various combinations of processing parameters had a decisive effect on the created superhydrophobicity, crosslink density (CD), replication quality (RQ), and the icephobic properties of the produced surfaces. Therefore, to evaluate the effect of processing parameters on these properties of the micro compression-molded SR surfaces, we used response surface methodology. Part thickness, molding pressure, and their interaction were the significant processing parameters affecting the CA. However, for different part thicknesses, increasing the pressure produced divergent effects. For the 3-mm and 6-mm thicknesses, an optimal pressure was observed to achieve the highest $\mathrm{CA}$, whereas at 9-mm thickness, the greater the pressure, the higher the CA. The same parameters were determined as the significant factors affecting SA. Although there was an optimal pressure for parts being 3-mm thick to achieve the lowest SA, a greater thickness required a higher pressure to attain a low SA. All parameters for CD were significant; however, curing time, mold temperature, and their interaction were the most significant factors. An optimal temperature achieved the highest $\mathrm{CD}$ as increasing the temperature also increased in decomposition rate. The highest RQs were obtained at lower, middle, and higher pressures for 3$\mathrm{mm}, 6-\mathrm{mm}$, and 9-mm thicknesses, respectively. Surfaces having relatively lower solid-liquid area fraction $(f)$ showed a longer freezing delay due to the air pockets acting as thermal barriers and a lower water-surface contact area. Surfaces having lower kurtosis were most favorable for icephobic properties; however, this icephobicity is contingent on a low $f$ value.

\section{Acknowledgment}

The authors acknowledge the financial support from the Natural Sciences and Engineering Research Council of Canada (NSERC) and K-Line Insulators Limited, Toronto, Canada.

\section{References}

[1] Maghsoudi, K.; Jafari, R.; Momen, G.; Farzaneh, M., Micro-nanostructured polymer surfaces using injection molding: A review. Mater. Today Commun. 2017, 13, 126-143. DOI: 10.1016/j.mtcomm.2017.09.013. 
[2] Jafari, R.; Cloutier, C.; Allahdini, A.; Momen, G., Recent progress and challenges with 3D printing of patterned hydrophobic and superhydrophobic surfaces. Int. J. Adv. Manuf. Tech. 2019, 1-14. DOI: 10.1007/s00170-019-03630-4.

[3] Lu, Y.; Chen, F.; Wu, X.; Zhou, C.; Lou, Y.; Li, L., Fabrication of micro-structured polymer by micro injection molding based on precise micro-ground mold core. Micromachines 2019, 10 (4), 253. DOI: 10.3390/mi10040253.

[4] Juster, H.; van der Aar, B.; de Brouwer, H., A review on microfabrication of thermoplastic polymer-based microneedle arrays. Polym. Eng. Sci. 2019, 59 (5), 877-890. DOI: 10.1002/pen.25078.

[5] Sha, B.; Dimov, S.; Griffiths, C.; Packianather, M., Investigation of micro-injection moulding: Factors affecting the replication quality. J. Mater. Process. Technol. 2007, 183 (2-3), 284-296. DOI: 10.1016/j.jmatprotec.2006.10.019.

[6] Hopmann, C.; Behmenburg, C.; Recht, U.; Zeuner, K., Injection molding of superhydrophobic liquid silicone rubber surfaces. Silicon 2014, 6 (1), 35-43. DOI: 10.1007/s12633-013-9164-0.

[7] Mulroney, A. T.; Gupta, M. C., Optically transparent superhydrophobic polydimethylsiloxane by periodic surface microtexture. Surf. Coat. Technol. 2017, 325, 308-317. DOI: 10.1016/j.surfcoat.2017.06.066.

[8] Masato, D.; Sorgato, M.; Lucchetta, G., Analysis of the influence of part thickness on the replication of micro-structured surfaces by injection molding. Mater. Design 2016, 95, 219-224. DOI: 10.1016/j.matdes.2016.01.115.

[9] Wlodarski, P.; Pittman, J., Replication of surface micro-features using variothermal injection molding: Application to micro-fluidics. Polym. Eng. Sci. 2018, 58 (10), 1726-1738. DOI: 10.1002/pen.24772.

[10] Lu, Y.; Chen, F.; Wu, X.; Zhou, C.; Zhao, H.; Li, L.; Tang, Y., Precise WEDM of microtextured mould for micro-injection molding of hydrophobic polymer surface. Mater. Manuf. Processes 2019, 34 (12), 1342-1351. DOI: 10.1080/10426914.2019.1660784.

[11] Søgaard, E., Injection molded self-cleaning surfaces. 2014.

[12] Baruffi, F.; Calaon, M.; Tosello, G., Effects of micro-injection moulding process parameters on accuracy and precision of thermoplastic elastomer micro rings. Precis. Eng. 2018, 51, 353-361. DOI: 10.1016/j.precisioneng.2017.09.006.

[13] Saarikoski, I.; Joki-Korpela, F.; Suvanto, M.; Pakkanen, T. T.; Pakkanen, T. A., Superhydrophobic elastomer surfaces with nanostructured micronails. Surf. Sci. 2012, 606 (1-2), 91-98. DOI: 10.1016/j.susc.2011.09.005.

[14] Vazirinasab, E.; Jafari, R.; Momen, G., Application of superhydrophobic coatings as a corrosion barrier: A review. Surf. Coat. Technol. 2018, 341, 40-56. DOI: 10.1016/j.surfcoat.2017.11.053.

[15] Zhang, B.-X.; Wang, S.-L.; Wang, X.-D., Wetting Transition from the Cassie-Baxter state to the Wenzel state on regularly nanostructured surfaces induced by an electric field. Langmuir 2019, 35 (3), 662-670. DOI: 10.1021/acs.langmuir.8b03808.

[16] Weng, C.; Wang, F.; Zhou, M.; Yang, D.; Jiang, B., Fabrication of hierarchical polymer surfaces with superhydrophobicity by injection molding from nature and function-oriented design. Appl. Surf. Sci. 2018, 436, 224-233. DOI: 10.1016/j.apsusc.2017.11.268.

[17] Zhan, Z.; Li, Z.; Li, X.; Garcell, E.; Singh, S.; ElKabbash, M.; Guo, C., Creating Superhydrophobic Polymer Surfaces with Superstrong Resistance to Harsh Cleaning and 
Mechanical Abrasion Fabricated by Scalable One-Step Thermal-Imprinting. Adv. Mater. Interfaces 2019, 1900240. DOI: 10.1002/admi.201900240.

[18] Maghsoudi, K.; Momen, G.; Jafari, R.; Farzaneh, M., Rigorous testing to assess the selfcleaning properties of an ultra-water-repellent silicone rubber surface. Surf. Coat. Technol. 2019, 374, 557-568. DOI: 10.1016/j.surfcoat.2019.05.073.

[19] Wang, Q.; Wang, F.; Cheng, K., Effect of crosslink density on some properties of electron beam-irradiated styrene-butadiene rubber. Radiat. Phys. Chem. 2009, 78 (11), 1001-1005. DOI: 10.1016/j.radphyschem.2009.06.001.

[20] Bibiao, J.; Yang, Y.; Xiang, J.; Rongqi, Z.; Jianjun, H.; Wenyun, W., Preparation of hyperbranched polymers by self-condensing vinyl radical polymerization. Eur. Polym. J. 2001, 37 (10), 1975-1983. DOI: 10.1016/S0014-3057(01)00100-8.

[21] Lu, Y. L.; Li, Z.; Mao, L. X.; Li, Y.; Wu, Y. P.; Liang, Y. R.; Zhang, L. Q., Impact of curing temperature on microstructures and properties of isobutylene-isoprene rubber/clay nanocomposites. Appl. Polym. Sci. 2008, 110 (2), 1034-1042. DOI: 10.1002/app.28690.

[22] Fan, R. L.; Zhang, Y.; Li, F.; Zhang, Y. X.; Sun, K.; Fan, Y. Z., Effect of high-temperature curing on the crosslink structures and dynamic mechanical properties of gum and N330-filled natural rubber vulcanizates. Polym. Test. 2001, 20 (8), 925-936. DOI: 10.1016/S01429418(01)00035-6

[23] Gadelmawla, E.; Koura, M.; Maksoud, T.; Elewa, I.; Soliman, H., Roughness parameters. J. Mater. Process. Technol. 2002, 123 (1), 133-145. DOI: 10.1016/S0924-0136(02)00060-2.

[24] Merola, M.; Ruggiero, A.; De Mattia, J. S.; Affatato, S., On the tribological behavior of retrieved hip femoral heads affected by metallic debris. A comparative investigation by stylus and optical profilometer for a new roughness measurement protocol. Measurement 2016, 90, 365-371. DOI: 10.1016/j.measurement.2016.05.003.

[25] Vazirinasab, E.; Maghsoudi, K.; Jafari, R.; Momen, G., A Comparative Study of the Icephobic and Self-Cleaning Properties of Teflon Materials Having Different Surface Morphologies. J. Mater. Process. Technol. 2019, 116415. DOI: 10.1016/j.jmatprotec.2019.116415.

[26] Sedlaček, M.; Podgornik, B.; Vižintin, J., Correlation between standard roughness parameters skewness and kurtosis and tribological behaviour of contact surfaces. Tribol. Int. 2012, 48, 102-112. DOI: $10.1016 /$ j.triboint.2011.11.008.

[27] Zhang, H.; Yang, H.; Shentu, B.; Chen, S.; Chen, M., Effect of titanium dioxide on the UVC ageing behavior of silicone rubber. J. Appl. Polym. Sci. 2018, 135 (14), 46099. DOI: 10.1002/app.46099.

[28] Flory, P. J.; Rehner Jr, J., Statistical mechanics of cross-linked polymer networks I. Rubberlike elasticity. J. Chem. Phys. 1943, 11 (11), 512-520. DOI: 10.1063/1.1723791.

[29] Ward, I. M.; Hadley, D. W., An introduction to the mechanical properties of solid polymers. 1993.

[30] Wang, X.; Xia, Z.; Yuan, B.; Zhou, H.; Li, Z.; Chen, N., Effect of curing temperature on the properties of conductive silicone rubber filled with carbonyl permalloy powder. Mater. Design 2013, 51, 287-292. DOI: 10.1016/j.matdes.2013.04.007.

[31] Vazirinasab, E.; Jafari, R.; Momen, G., Evaluation of atmospheric-pressure plasma parameters to achieve superhydrophobic and self-cleaning HTV silicone rubber surfaces via a single-step, eco-friendly approach. Surf. Coat. Technol. 2019, 375, 100-111. DOI: 10.1016/j.surfcoat.2019.07.005. 
[32] Cassie, A.; Baxter, S., Wettability of porous surfaces. Transactions of the Faraday Society 1944, 40, 546-551. DOI: 10.1039/TF9444000546.

[33] Irajizad, P.; Nazifi, S.; Ghasemi, H., Icephobic surfaces: Definition and figures of merit. Adv. Colloid Interfac. 2019. DOI: 10.1016/j.cis.2019.04.005.

[34] Yang, Q.; Luo, Z.; Jiang, F.; Luo, Y.; Tan, S.; Lu, Z.; Zhang, Z.; Liu, W., Air cushion convection inhibiting icing of self-cleaning surfaces. ACS Appl. Mater. Interfaces 2016, 8 (42), 29169-29178. DOI: 10.1021/acsami.6b10165.

[35] Varanasi, K. K.; Deng, T.; Smith, J. D.; Hsu, M.; Bhate, N., Frost formation and ice adhesion on superhydrophobic surfaces. Appl. Phys. Lett. 2010, 97 (23), 234102. DOI: $10.1063 / 1.3524513$. 